clinic of his fellow-countryman, the late John Couper. He was subsequently elected an Assistant Surgeon to the Central London Ophthalmic Hospital, but retained this position for only a few years. He became a member of the Ophthalmological Society of the United Kingdom, in 1889, and, until he gave up his house in town, was a fairly regular attendant at the meetings, which at that time were held once a month. From 1891 to 1899 he was Editor of The Ophthalmic Review. Although keenly interested in his subject he made but few contributions to the literature of ophthalmology : he read abundantly and widely, but was not fond of writing. MacLehose married a daughter of Alexander Macmillan, the publisher, and leaves one son and one daughter. His wife died some years ago, and a younger son fell in the war of 1914-1918.

\title{
CORRESPONDENCE
}

\section{THE FITTING OF CONTACT LENSES}

To the Editors of The British Journal of Ophthalmology.

Sirs.-Probably the major difficulties in the successful fitting of contact lenses are the elimination of air bubbles, and also of being able to stimulate the confidence of the patient by a rapid and simple technique in applying and removing the lenses.

From the available literature of the makers of these lenses, no guidance is given on the methods of fitting and therefore, as a result of many practical tests, the following observations are submitted in the hope that they may prove helpful, it having been discovered that by employing this technique, the fitting is simplified whilst eliminating the difficulty of the air bubbles.

In applying the rubber sucker to the contact lens prior to fitting, only a small portion of the air should be excluded, retaining just sufficient suction to hold the lens in position. It will be realized that when the lens is in situ, the easy removal of the sucker is of vital importance. The patient's head should naturally be held in a horizontal position over a towel or other soft material. Both eyelids should be well open and the lens inserted under the lower lid first, with the upper lid well extended clear of the contact lens. The patient is then asked to look directly downwards, and at the same time the lens is gently pressed on to the eye.

It is of the greatest importance that the lens should be applied to the eye very gently; only just sufficient suction is necessary to 
retain the lens in position without slipping. 'Too much pressure causes suction in the centre space of the contact lens over the pupil because of the tendency to create a vacuum, and causes discomfort. Both eyelids should then be released and allowed to traverse the contact lens before any attempt is made to remove the sucker, and then by firmly excluding all air from the sucker it will fall away very readily. In this way the contact lens is retained in position by just the right amount of contact suction and is correspondingly easy of removal.

To remove the lens from the eye all the air should be excluded from the sucker before applying, the end of the sucker being moistened with water. It should then be firmly pressed on to the contact lens. The sucker now has a firm grip of the lens, and it is possible by a downward leverage to transmit a pressure on to the lower rim of the contact lens which will cause it to admit air at its top edge and come easily away from the eye with a minimum of discomfort to the patient. It is not necessary by this method to use a probe or other instrument for the admission of air or leverage of the lens from the sclera.

Yours truly,

George Paxton.

195-199, Great Portland

STREET, W.1

\section{NOTES}

Death

As we go to press we learn, with much regret, of the death of Professor K. K. K.

Lundsgaard, of Copenhagen.

$\mathrm{I}_{\mathrm{N}}$ an account of Turberville of Salisbury in

Addendum to Vol. X, p. 465, it was stated that after his Turberville of Salisbury death, his sister, Mary Turberville, carried on his practice in London. Through the courtesy of Dr. George Peachey we are enabled to give a copy of her advertisement in the Press. It occurs in the London Gazette, June 5, 1701, and runs as follows: "Mrs. Mary Turbervile, sister to the late Dr. Turbervile of Salisbury, liveth in Little Lincoln's Inn, near the Grange Inn, and practises on diseases curable of the eye."

In the issue of June 9, of the same journal, is the advertisement of " Mons. Girard, oculist, who may be heard of at Mons. Buissière, surgeon, at the Blue Balcony in Suffolk Street, Pall Mall." Details 